\title{
Protective effects of deferasirox and N-acetyl-L- cysteine on iron overload-injured bone marrow
}

\author{
J.C. Shen ${ }^{1}$, Y.C. Zhang ${ }^{2}$ and M.F. Zhao ${ }^{3}$ \\ ${ }^{1}$ Department of Hematology, Affiliated Hospital of Logistics University of People's Armed Police Forces, Tianjin, China \\ ${ }^{2}$ Department of Biotherapy, Affiliated Hospital of Logistics University of People's Armed Police Forces, Tianjin, China \\ ${ }^{3}$ Department of Hematology, The First Central Hospital, Tianjin, China
}

\begin{abstract}
Using an iron overload mouse model, we explored the protective effect of deferasirox (DFX) and N-acetyl-L-cysteine (NAC) on injured bone marrow hematopoietic stem/progenitor cells (HSPC) induced by iron overload. Mice were intraperitoneally injected with $25 \mathrm{mg}$ iron dextran every 3 days for 4 weeks to establish an iron overload (Fe) model. DFX or NAC were co-administered with iron dextran in two groups of mice (Fe + DFX and Fe + NAC), and the function of HSPCs was then examined. Iron overload markedly decreased the number of murine HSPCs in bone marrow. Subsequent colony-forming cell assays showed that iron overload also decreased the colony forming capacity of HSPCs, the effect of which could be reversed by DFX and NAC. The bone marrow hematopoiesis damage caused by iron overload could be alleviated by DFX and NAC.
\end{abstract}

Key words: Iron overload; Bone marrow; Hematopoietic stem/progenitor cells; Deferasirox; N-acetyl-L-cysteine

\section{Introduction}

Several patients with ineffective hematopoiesis and cytopenia, such as aplastic anemia (1), myelodysplastic syndromes (MDS) $(2,3)$, myelofibrosis (4-6), and $\beta$-thalassemia $(7,8)$, require multiple erythrocyte transfusions leading to iron overload $(9,10)$. The clinical characterization of iron overload includes hepatic dysfunction, cardiac dysfunction, glucose intolerance, arthropathy, sexual dysfunction and fatigue (11-17).

Recently, it was reported that rapid accumulation of excessive iron negatively affects the hematopoietic system by damaging hematopoietic cells and hematopoietic microenvironment (18). Some clinical evidence indicates that iron chelation therapy (ICT) can improve hematopoiesis and exert a survival benefit in iron overload patients with low-risk MDS (18-22). Deferasirox (DFX) is an oral iron chelator used to treat iron overload. Several studies indicate that DFX can efficiently improve the hematologic parameters, though the exact mechanism is still unknown $(6,22-26)$. On the other hand, our previous studies indicate that iron overload injures hematopoietic stem cells (HSCs) and mesenchymal stem cells (MSCs) via reactive oxygen species (ROS)-related signaling proteins and subsequent increased cell apoptosis and decreased cell proliferation (18,27-30). Using an antioxidant such as N-acetyl-Lcysteine (NAC) to decrease ROS levels partially attenuates bone marrow mononuclear cell (BMMNC) and umbilical cord-derived MSC injury in vitro $(14,31)$.

Despite the above findings, more evidence is needed to determine if iron overload impairs hematopoietic function by enhancing oxidative stress and how DFX and NAC exert their protective effects in vivo. Therefore, in this study, we established an iron overload model. Then, we investigated the general characteristics of bone marrow HSPC and the related signaling pathway in this process. Finally, we assayed for the effects of DFX and NAC in this model.

\section{Material and Methods}

\section{Animal model and treatment}

C57BL/6-Ly-5.1 (Ly5.1) male mice were obtained from the Institute of Peking University Health Science Center (Beijing, China). The mice were bred at a certified animal care facility in the Institute of Radiation Medicine of Peking Union Medical College (PUMC). All mice were used at approximately $6-8$ weeks of age, and the average weight was $20 \mathrm{~g}$.

First, the iron overload mouse model was established by intraperitoneal injection of varying doses $(12.5,25$, or $50 \mathrm{mg}$ ) of iron dextran (Sigma-Aldrich, USA) in $1 \mathrm{~mL}$ saline every 3 days for 2,4 , or 6 weeks. Ultimately, we chose

Correspondence: M.F. Zhao: <sjczyc2015@sina.com> | <mingfengzhao@sina.com> 
$25 \mathrm{mg} / \mathrm{mL}$ as the final dose (18). Next, the mice were randomly divided into four groups: control group, iron overload (Fe) group (25 mg/mL), Fe+DFX (Novartis, Switzerland) group, and Fe + NAC (Sigma-Aldrich) group. The experimental groups were intraperitoneally injected with $25 \mathrm{mg}$ of iron dextran (Sigma-Aldrich) twice a week for 4 weeks. Control group mice were injected with the same volume of saline (Sigma-Aldrich). The DFX powder (Novartis) was suspended in $0.5 \%$ aqueous Klucel hydroxypropylcellulose by ultrasonication, and $\mathrm{Fe}+\mathrm{DFX}$ group mice received $125 \mathrm{mg} / \mathrm{kg} \mathrm{DFX}$ by gavage 5 days per week. For NAC (Sigma-Aldrich) treatment, mice were given 40 mM NAC (Sigma-Aldrich) in their drinking water. The water bottles were exchanged twice weekly with a freshly prepared NAC solution (31). All treatments met local regulations and ethical requirements.

\section{Identification of iron overload mouse model}

The deposition of iron into LSK cells (Lin-Sca-1 + c-kit + ) was assessed using hematoxylin and eosin (HE) staining and Perls' iron staining. Additionally, the labile iron pool (LIP) level of LSKs was measured using a Calcein-AM fluorescent dye (Sigma-Aldrich) (32). The LSKs were analyzed using a flow cytometer with the mean fluorescence intensity (MFI) calculated by the Cell Quest software (BD Bioscience, USA).

\section{BMMNC counts}

The BMMNCs were flushed from the bones as previously described $(31,33,34)$ and were counted using a pocH-100i hematology analyzer (Sysmex, Japan). Mice were sacrificed by cervical dislocation and then liberally rinsed in a beaker with $100 \mathrm{~mL}$ of $70 \%(\mathrm{v} / \mathrm{v})$ ethanol for $3 \mathrm{~min}$. An incision was made through the skin, and the muscles were dissociated. The muscles and tendons were then cleaned from humeri, tibiae, and femurs. Removal of the epiphyses was performed with sterile scissors. The bone marrow was thoroughly flushed with a syringe needle containing $3 \mathrm{~mL}$ of alpha modified eagle medium ( $\alpha-\mathrm{MEM}$, Gibco, USA) and used for the following experiments.

\section{Flow cytometric assay}

The BMMNCs were stained with PE-conjugated antiTer-119 or the biotin-conjugated antibodies $\mathrm{Gr}-1$ and CD11b; the streptavidin APC-CY7 was incubated with DCFH-DA $(10 \mu \mathrm{M})$ or calcein-AM $(0.125 \mu \mathrm{M})$ in a humidified atmosphere of $5 \% \mathrm{CO}_{2}$ in air at $37^{\circ} \mathrm{C}$ for $15 \mathrm{~min}$. The hematopoietic progenitor cells (HPCs) (Lineage $/$ Sca- $1^{-} / \mathrm{c}-\mathrm{kit}^{+}, \mathrm{LSK}^{-}$) and HSCs (Lineage $/$ Sca- $1^{+} / \mathrm{c}^{-} \mathrm{kit}^{+}$; $\mathrm{LSK}^{+}$) were analyzed as previously described (14), and the levels of intracellular ROS and LIP were analyzed by measuring the MFI of $2^{\prime}-7^{\prime}$ dichlorofluorescein or calcein using a flow cytometer.

\section{Colony-forming cell (CFC) assay}

CFC assays were performed using BMMNCs in MethoCult GF M3434 methylcellulose medium (Stem Cell
Technologies, Canada). Colony-forming unit granulocytemacrophage (CFU-GM), colony-forming unit erythroid (CFU-E), burst-forming unit erythroid (BFU-E), and colonyforming unit mix (CFU-Mix) were counted on days 5, 7, 9, and 12 , respectively, using a microscope according to the manufacturer's protocol.

\section{Analysis of HSCs and HPCs by flow cytometry and establishment of co-culture system}

BMMNCs were incubated with biotin-conjugated rat antibodies specific for murine CD5, Mac-1, CD45R/B220, Ter-119, and Gr-1 for $15 \mathrm{~min}$ at room temperature. After washing with PBS twice, the cells were stained with APC-Cy7-conjugated streptavidin,PE-Cy7-conjugated antiSca1, and Alexa Fluor 700-conjugated anti-c-kit antibodies (eBioscience, USA) and analyzed by flow cytometry. The ratio of HPCs $\left(\mathrm{LSK}^{-}\right)$and $\mathrm{HSCs}\left(\mathrm{LSK}^{+}\right)$in BMMNCs was calculated.

\section{Single-cell colony assay}

Sorted $\mathrm{CD} 34^{-} / \mathrm{LSK}^{+}$cells were seeded onto the wells of 96-well round-bottom microplates using a BD FACS (USA) Aria III cell sorter at a density of 1 cell/well. The cells were cultured in $200 \mathrm{~mL}$ IMDM supplemented with $10 \%$ fetal calf serum, $1 \%$ bovine serum albumin, $2 \mathrm{mM}$ L-glutamine, $50 \mathrm{mM}$ 2-b-mercaptoethanol, $10 \mathrm{ng} / \mathrm{mL}$ stem cell factor, $10 \mathrm{ng} / \mathrm{mL}$ thrombopoietin, and $10 \mathrm{ng} / \mathrm{mL} \mathrm{IL-3}$, as described previously (14). After 14 days of culture, the colonies of cells with $\geqslant 50$ cells/well were scored under an inverted microscope. The results are reported as the number of colonies per 20 wells.

\section{Statistical analysis}

All experiments were performed at least three times. The results are reported as means $\pm S D$. Multiple group comparisons were performed using analysis of variance (ANOVA). Differences were considered to be statistically significant at $\alpha=0.05$, and Bonferroni correction was applied for multiple comparison tests. Analyses were performed with the GraphPad Prism program (GraphPad Software, Inc., USA).

\section{Ethics statement}

This study was approved by the PUMC Ethics Committee (No. 2012-0504). Evaluation of the handling of the experimental animals included: 1) the experiment, in which the needs of the animals were fully considered, including physiological (adequate food, water, temperature, and illumination), environmental, psychological, and social needs (socially raised, 4-6 animals per cage, avoiding fatigue and overstimulation). The outcomes of the preliminary experiment and the primary literature were taken into consideration to rationally design the sample size and operation standards. 2) Daily observation was performed to prevent the animals from anger, comfortlessness, fear, nervousness, pain or damage, as well as to 
maintain them at baseline status. Abuse and excessive or incorrect medication were avoided. For subcutaneous injection, narcotics were not provided. For tail vein injection, intraperitoneal anesthesia was given to alleviate pain. 3) At the end of the experiment, the animals were sacrificed within $15 \mathrm{~s}$ to avoid nervousness of the other animals.

\section{Results}

\section{Establishment of BM iron overload mouse model}

To confirm the efficacy of bone marrow iron overload mouse model, the LIP levels of the BMMNC were evaluated. When the mice were injected with $25 \mathrm{mg} / \mathrm{mL}$ iron dextran for 4 weeks, the calcein AM fluorescence intensity of BMMNC in the iron overload (Fe) group (MFI: 229, $774 \pm 28,423$ ) was lower than the control group (MFI: 496,300 $\pm 76,698 ; P<0.05$; Figure $1 \mathrm{~A}$ ), which indicated a higher LIP level in the bone marrow of Fe group mice. Furthermore, bone marrow iron deposits were assessed at the end of fourth week. Iron deposits were easily observed in the bone marrow of Fe group mice (Figure 1B). These results demonstrated that the experimental murine model reflected an iron overload pathogenic condition.

\section{Ratios of HPCs (LSK ${ }^{-}$) and HSCs $\left(\mathrm{LSK}^{+}\right)$in iron overload BMMNCs}

The ratios of HPCs and HSCs in bone marrow were analyzed by flow cytometry (Figure $2 \mathrm{~A}$ ), and we found that iron overload significantly decreased the frequency of HPCs and HSCs. Notably, this effect was totally reversed by treatment with DFX or NAC (Figure $2 \mathrm{~B}$ and $\mathrm{C}, \mathrm{P}<0.001$ compared to the Fe group). Furthermore, there was no
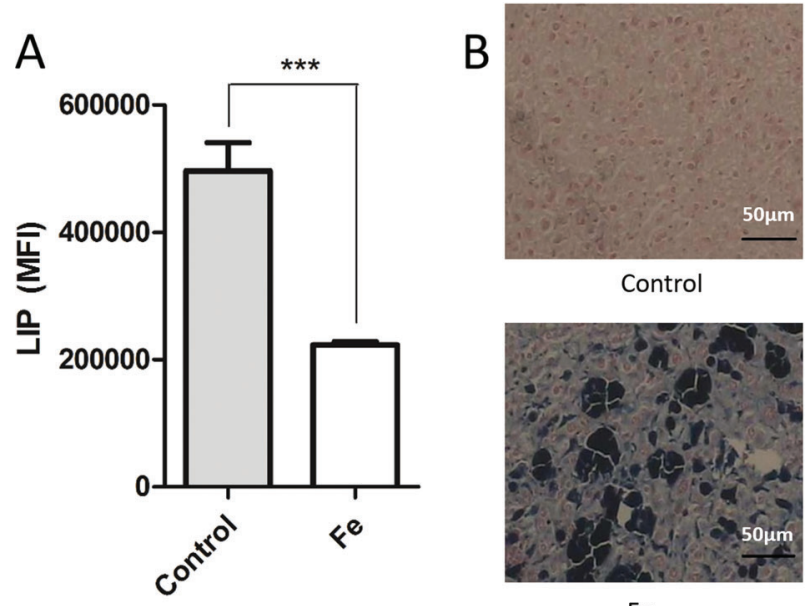

Control

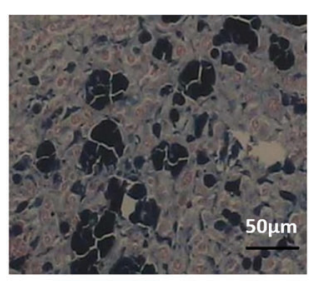

$\mathrm{Fe}$

Figure 1. Establishment of an iron overload $(\mathrm{Fe})$ mouse model. $A$, labile iron pool (LIP) level in bone marrow mononuclear cells after $25 \mathrm{mg} / \mathrm{mL}$ iron dextran treatment, mean fluorescence intensity (MFI). Data are reported as means $\pm \mathrm{SD}$. ${ }^{* \star *} \mathrm{P}<0.001$, ANOVA. $B$, Bone marrow analyzed by Perl's iron staining $(\times 1000)$. significant difference in the number of HPCs and HSCs between $\mathrm{Fe}+\mathrm{DFX}$ and $\mathrm{Fe}+\mathrm{NAC}$ groups, which indicated a similar effect of DFX and NAC.

\section{LIP levels of LSK ${ }^{+}$cells}

The LIP levels of Fe mice were significantly increased (MFI: $229,774 \pm 28,423 ; \mathrm{P}<0.001$ ) compared to the control group (Figure 3 ). However, this was significantly reversed by the administration of DFX (MFI: $304,585 \pm 3,899$ ) and NAC (MFI: $317,429 \pm 19,778)$ compared to the Fe group $(\mathrm{P}<0.001)$.

\section{ROS levels of $\mathrm{LSK}^{+}$cells}

The ROS levels of $\mathrm{LSK}^{+}$cells significantly increased in the Fe mice compared to the control group $(P<0.05)$, whereas DFX or NAC treatment significantly inhibited the production of ROS in iron overloaded HSPC compared to the Fe group $(\mathrm{P}<0.05$, Figure 4).

\section{Bone marrow CFCs}

BMMNCs derived from each group were grown in triplicate in M3434 semi-solid media. As shown in Figure 5, CFCs counts (CFU-E, CFU-GM, BFU-E, and CFU-mix) in the Fe group were significantly decreased compared to the control group (all $\mathrm{P}<0.001$ ), and this effect was significantly reversed by DFX and NAC compared to the Fe group (all $\mathrm{P}<0.05$ ). Furthermore, the clonogenic capacity of HSPCs was decreased by iron overload $(P<0.01)$, and this effect was improved after administration of DFX $(P<0.01)$. However, no obvious improvement was observed in the NAC group (Figure 6; $\mathrm{P}>0.05$ compared to the control group).

\section{Discussion}

Transfusional iron overload refers to excessive iron deposition in the body, which can lead to abnormal hematopoietic function. In this study, using a novel iron overload mouse model, we observed that excessive iron deposition decreased the number of bone marrow HSPCs. Furthermore, iron overload affected the function of HSPCs, as indicated by a significant reduction of CFUs number and a decreased single-cell clone formation capacity. Importantly, all of these iron overload-induced damages were reversible via iron-chelation (DFX) or anti-oxidation (NAC) treatment.

Clinical evidence shows that ICT can improve hematological parameters and decrease transfusion requirements in MDS patients (35). As an iron chelating agent, deferoxamine (DFO) has been widely used for the treatment of secondary iron overload and displays an antiproliferative activity against a wide range of tumors $(36,37)$. However, its high hydrophilicity and short half-life limit the effect of DFO. Serious Listeria monocytogenes infections have also been reported in secondary iron overload mice intraperitoneally injected with DFO (38). 

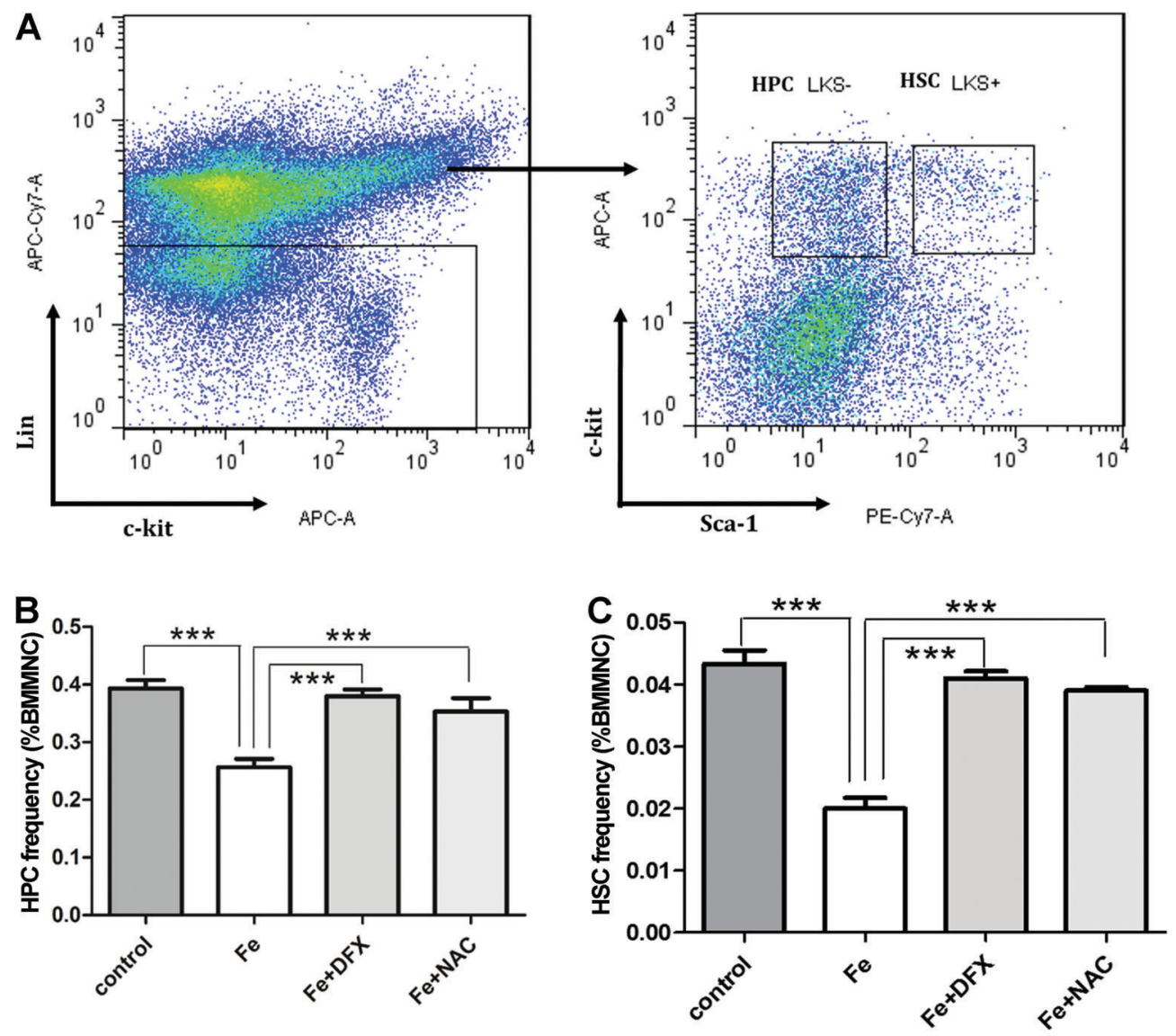

Figure 2. Flow cytometric profile of Lin-Sca- $1+c-k i t(L K S)^{-}$hematopoietic progenitor cells (HPCs) and LKS $^{+}$hematopoietic stem cells (HSCs) cells $(A)$. Decreased ratio of HPCs $(B)$ and HSCs $(C)$ in iron overload (Fe) bone marrow mononuclear cells (BMMNCs) reversed by deferasirox (DFX) or $\mathrm{N}$-acetyl-L-cysteine (NAC). Data are reported as means $\pm \mathrm{SD}$. ${ }^{* * *} \mathrm{P}<0.001$ (ANOVA).

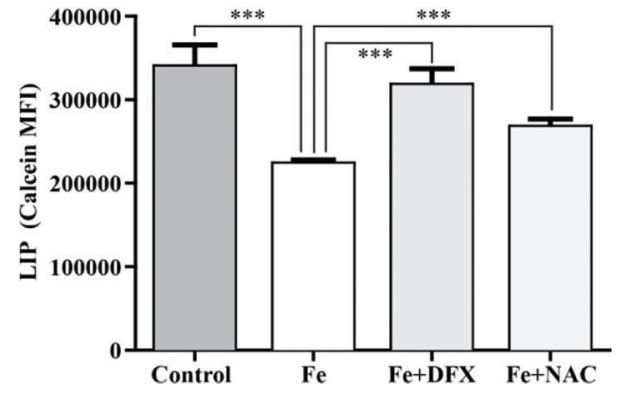

Figure 3. Labile iron pool (LIP) levels of Lin-Sca-1 + c-kit (LSK) ${ }^{+}$ in iron overload mice (Fe) significantly increased compared to the control group and were reversed by the administration of deferasirox (DFX) or N-acetyl-L-cysteine (NAC) in mean fluorescence intensity $(\mathrm{MFI})$. Data are reported as means $\pm \mathrm{SD}$. ${ }^{* * *} \mathrm{P}<0.001$, ANOVA.

Overcoming these limitations, the oral agent DFX also shows significant anti-proliferative activity against hepatoma and myeloid malignant tumors (39). In addition, it was

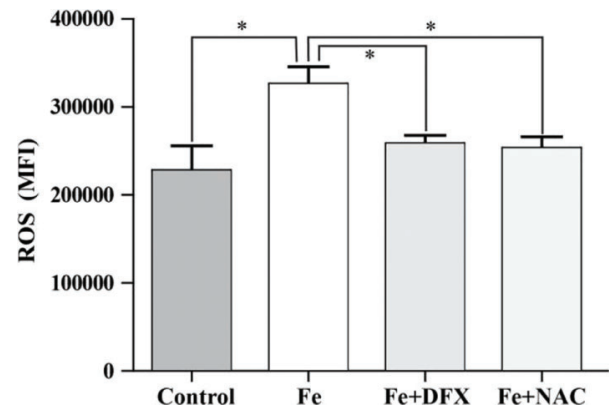

Figure 4. Reactive oxygen species (ROS) levels of Lin-Sca-1+ c-kit $(\mathrm{LSK})^{+}$cells in iron overload $(\mathrm{Fe})$ mice and after the administration of deferasirox (DFX) or N-acetyl-L-cysteine (NAC), in mean fluorescence intensity (MFI). Data are reported as means $\pm S D$. ${ }^{*} \mathrm{P}<0.05$ (ANOVA).

found that iron overload significantly delays hematopoietic recovery after bone marrow transplantation, which indicates that iron overload may impact the hematopoietic 

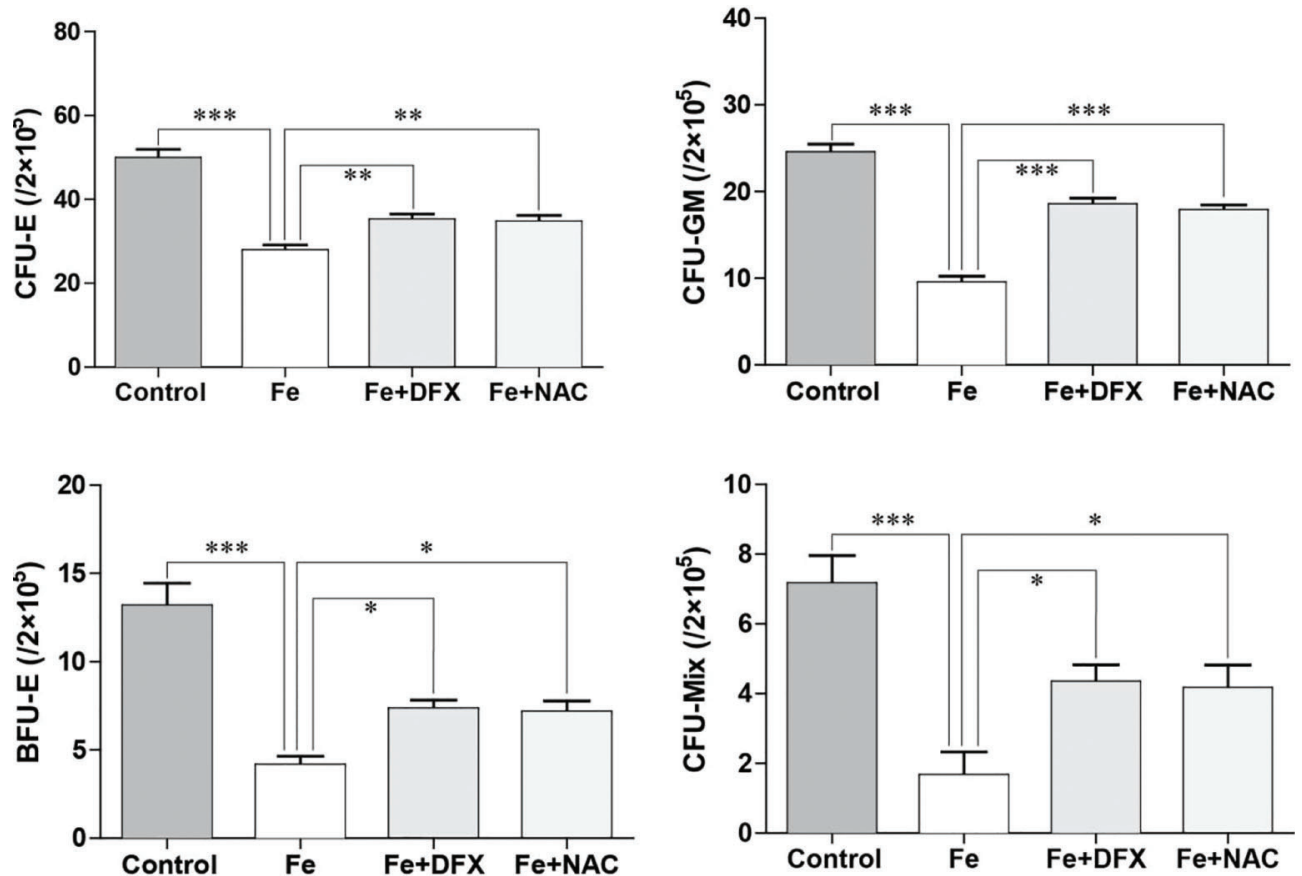

Figure 5. Results of colony-forming unit erythroid (CFU-E), granulocyte-macrophage (CFU-GM), burst-forming unit erythroid (BFU-E), and colony-forming unit mix (CFU-Mix) assays of bone marrow of iron overload (Fe) mice and after the administration of deferasirox (DFX) or $\mathrm{N}$-acetyl-L-cysteine (NAC). Data are reported as means $\pm \mathrm{SD}$. ${ }^{*} \mathrm{P}<0.05$, ${ }^{* \star} \mathrm{P}<0.01$, and ${ }^{* * *} \mathrm{P}<0.001$ (ANOVA).

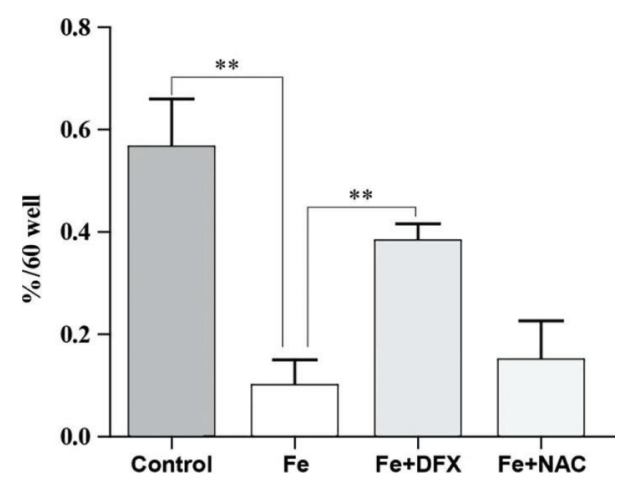

Figure 6. Clonogenic capacity of hematopoietic stem/progenitor cells (HSPCs) in iron overload ( $\mathrm{Fe}$ ) mice and after the administration of deferasirox (DFX) or N-acetyl-L-cysteine (NAC). Data are reported as means $\pm S D$. ${ }^{* *} \mathrm{P}<0.01$ (ANOVA).

microenvironment of bone marrow (23). We recently confirmed the toxic effect of free iron on HSPCs and supported the protective efficiency of DFX in hematopoietic recovery $(14,25)$.

The inhibitory effect of iron overload is mainly related to the activation of intracellular ROS. It has been confirmed that iron overload occurring through mediated oxidative stress can result in tissue damage in a diabetic animal model (38). ROS is mainly created through NADPH in the mitochondria (40). Under normal physiological conditions, intracellular ROS stays at a low level, but under stress or damage conditions, increasing levels of active oxygen lead to protein, cell membrane, and DNA damage, which can result in aging and apoptosis of hematopoietic cells (18). We found that iron overload increases the ROS level of HSPCs and impacts hematopoietic function, whereas the anti-oxidant NAC improves this situation. These data confirm the ROS involvement in iron overload-induced HSPC damage and indicate that NAC is an option for iron overload therapy.

In conclusion, the iron overload mouse model was successfully established for further experiments. Iron overloadinduced damage to bone marrow HSPCs could be partially improved by the iron-chelating agent DFX or the antioxidant NAC.

\section{Acknowledgments}

This work was supported by grants from the National Natural Sciences Foundation of Tianjin (No. 17JCZDJC35800), the Tianjin Science and Technique Foundation (Nos. 13KG106 and 2013KR07), and the Seed Foundation of Affiliated Hospital of Logistics University of People's Armed Police Forces (No. FYM201408). 


\section{References}

1. Lee SE, Yahng SA, Cho BS, Eom KS, Kim YJ, Lee S, et al. Improvement in hematopoiesis after iron chelation therapy with deferasirox in patients with aplastic anemia. Acta Haematol 2013; 12972-12977, doi: 10.1159/000342772.

2. Bennett JM. Consensus statement on iron overload in myelodysplastic syndromes. Am J Hematol 2008; 83: 858-861, doi: 10.1002/ajh.21269.

3. Pullarkat V. Objectives of iron chelation therapy in myelodysplastic syndromes: more than meets the eye? Blood 2009; 114: 5251-5255, doi: 10.1182/blood-2009-07-234062.

4. Smeets ME, Vreugdenhil G, Holdrinet RS. Improvement of erythropoiesis during treatment with deferiprone in a patient with myelofibrosis and transfusional hemosiderosis. $A m \mathrm{~J}$ Hematol 1996; 51: 243-244, doi: 10.1002/(SICl)1096-8652 (199603)51:3 < 243::AID-AJH12 > 3.0.CO;2-H.

5. Di Tucci AA, Murru R, Alberti D, Rabault B, Deplano S, Angelucci $\mathrm{E}$. Correction of anemia in a transfusion-dependent patient with primary myelofibrosis receiving iron chelation therapy with deferasirox (Exjade, ICL670). Eur J Haematol 2007; 78: 540-542, doi: 10.1111/j.1600-0609.2007.00840.x.

6. Cilloni D, Messa F, Arruga F, Roetto A, Saglio G. Deferasirox treatment improved the hemoglobin level and decreased transfusion requirements in four patients with the myelodysplastic syndrome and primary myelofibrosis. Acta Haematol 2008; 120: 70-74, doi: 10.1159/000158631.

7. Cappellini MD, Cohen A, Piga A, Bejaoui M, Perrotta S, Agaoglu L, et al. A phase 3 study of deferasirox (ICL670), a once-daily oral iron chelator, in patients with betathalassemia. Blood 2006; 107: 3455-3462, doi: 10.1182/ blood-2005-08-3430.

8. Piga A, Galanello R, Forni GL, Cappellini MD, Origa R, Zappu A, Donato $G$, et al. Randomized phase II trial of deferasirox (Exjade, ICL670), a once-daily, orally-administered iron chelator, in comparison to deferoxamine in thalassemia patients with transfusional iron overload. Haematologica 2006; 91: 873-880.

9. Balducci L. Transfusion independence in patients with myelodysplastic syndromes: impact on outcomes and quality of life. Cancer 2006; 106: 2087-2094, doi: 10.1002/cncr.21860.

10. Platzbecker U, Hofbauer LC, Ehninger G, Hölig K. The clinical, quality of life, and economic consequences of chronic anemia and transfusion support in patients with myelodysplastic syndromes. Leuk Res 2012; 36: 525-536, doi: 10.1016/ j.leukres.2012.01.006.

11. McLaren GD, Muir WA, Kellermeyer RW. Iron overload disorders: natural history, pathogenesis, diagnosis, and therapy. Crit Rev Clin Lab Sci 1983; 19: 205-266, doi: 10.3109/ 10408368309165764

12. Kushner JP, Porter JP, Olivieri NF. Secondary iron overload. Hematology Am Soc Hematol Educ Program 2001: 47-61, doi: 10.1182/asheducation-2001.1.47.

13. Takatoku M, Uchiyama T, Okamoto S, Kanakura Y, Sawada $\mathrm{K}$, Tomonaga M, et al. Retrospective nationwide survey of Japanese patients with transfusion-dependent MDS and aplastic anemia highlights the negative impact of iron overload on morbidity/mortality. Eur J Haematol 2007; 78: 487-494, doi: 10.1111/j.1600-0609.2007.00842.x.

14. Lu W, Zhao M, Rajbhandary S, Xie F, Chai X, Mu J, et al. Free iron catalyzes oxidative damage to hematopoietic cells/mesenchymal stem cells in vitro and suppresses hematopoiesis in iron overload patients. Eur $\mathrm{J}$ Haematol 2013; 91: 249-261, doi: 10.1111/ejh.12159.

15. Bassett ML, Halliday JW, Powell LW. Value of hepatic iron measurements in early hemochromatosis and determination of the critical iron level associated with fibrosis. Hepatology 1986; 6: 24-29, doi: 10.1002/hep.1840060106.

16. De Sanctis V, Zurlo MG, Senesi E, Boffa C, Cavallo L, Di Gregorio F. Insulin dependent diabetes in thalassaemia. Arch Dis Child 1988; 63: 58-62, doi: 10.1136/adc.63.1.58.

17. Malcovati L, Porta MG, Pascutto C, Invernizzi R, Boni M, Travaglino $\mathrm{E}$, et al. Prognostic factors and life expectancy in myelodysplastic syndromes classified according to WHO criteria: a basis for clinical decision making. J Clin Oncol 2005; 23: 7594-7603, doi: 10.1200/JCO.2005.01.7038.

18. Okabe H, Suzuki T, Uehara E, Ueda M, Nagai T, Ozawa K. The bone marrow hematopoietic microenvironment is impaired in iron-overloaded mice. Eur J Haematol 2014; 93: 118-128, doi: 10.1111/ejh.12309.

19. Gattermann N. Overview of guidelines on iron chelation therapy in patients with myelodysplastic syndromes and transfusional iron overload. Int J Hematol 2008; 88: 24-29, doi: 10.1007/s12185-008-0118-z.

20. Remacha AF, Arrizabalaga B, Del Cañizo C, Sanz G, Villegas A. Iron overload and chelation therapy in patients with low-risk myelodysplastic syndromes with transfusion requirements. Ann Hematol 2010; 89: 147-154, doi: 10.1007/ s00277-009-0794-7.

21. Delforge $M$, elleslag $D$, Beguin $Y$, Triffet $A$, Mineur $P$, Theunissen K, et al. Adequate iron chelation therapy for at least six months improves survival in transfusion-dependent patients with lower risk myelodysplastic syndromes. Leuk Res 2014; 38: 557-563, doi: 10.1016/j.leukres.2014.02.003.

22. Gattermann N, Finelli C, Della Porta M, Fenaux P, Stadler M, Guerci-Bresler A, et al. Hematologic responses to deferasirox therapy in transfusion-dependent patients with myelodysplastic syndromes. Haematologica 2012; 97: 1364-1371, doi: 10.3324/haematol.2011.048546.

23. Okabe H, Suzuki T, Omori T, Mori M, Uehara E, Hatano K, et al. Hematopoietic recovery after administration of deferasirox for transfusional iron overload in a case of myelodysplastic syndrome. Rinsho Ketsueki 2009; 50: 1626-1629.

24. List AF, Baer MR, Steensma DP, Raza A, Esposito J, Martinez-Lopez N, et al. Deferasirox reduces serum ferritin and labile plasma iron in RBC transfusion-dependent patients with myelodysplastic syndrome. J Clin Oncol 2012. 30: 21342149, doi: 10.1200/JCO.2010.34.1222.

25. Oliva EN, Ronco F, Marino A, Alati C, Praticò G, Nobile F. Iron chelation therapy associated with improvement of hematopoiesis in transfusion-dependent patients. Transfusion 2010; 50: 1568-1570, doi: 10.1111/j.1537-2995.2010. 02617.x.

26. Guariglia R, Martorelli MC, Villani O, Pietrantuono G, Mansueto G, D'Auria F, et al. Positive effects on hematopoiesis in patients with myelodysplastic syndrome receiving deferasirox as oral iron chelation therapy: a brief review. Leuk Res 2011; 35: 566-570, doi: 10.1016/j.leukres.2010.11.027.

27. Tothova Z, Kollipara R, Huntly BJ, Lee BH, Castrillon DH, Cullen DE, et al. FoxOs are critical mediators of hematopoietic 
stem cell resistance to physiologic oxidative stress. Cell 2007; 128: 325-339, doi: 10.1016/j.cell.2007.01.003.

28. Heo JY, Jing K, Song KS, Seo KS, Park JH, Kim JS, et al. Downregulation of APE1/Ref-1 is involved in the senescence of mesenchymal stem cells. Stem Cells 2009; 27: 1455-1462, doi: 10.1002/stem.54.

29. Jang $Y Y$, Sharkis SJ. A low level of reactive oxygen species selects for primitive hematopoietic stem cells that may reside in the low-oxygenic niche. Blood 2007; 110: 30563063, doi: 10.1182/blood-2007-05-087759.

30. Shao L, Li H, Pazhanisamy SK, Meng A, Wang Y, Zhou D. Reactive oxygen species and hematopoietic stem cell senescence. Int J Hematol 2011; 94: 24-32, doi: 10.1007/ s12185-011-0872-1.

31. Wang Y, Liu L, Pazhanisamy SK, Li H, Meng A, Zhou D, et al. Total body irradiation causes residual bone marrow injury by induction of persistent oxidative stress in murine hematopoietic stem cells. Free Radic Biol Med 2010; 48: 348-356, doi: 10.1016/j.freeradbiomed.2009.11.005.

32. Richardson DR, Ponka P. The molecular mechanisms of the metabolism and transport of iron in normal and neoplastic cells. Biochim Biophys Acta 1997; 1331: 1-40, doi: 10.1016/ S0304-4157(96)00014-7.

33. Meng A, Wang Y, Brown SA, Van Zant G, Zhou D. lonizing radiation and busulfan inhibit murine bone marrow cell hematopoietic function via apoptosis-dependent and -independent mechanisms. Exp Hematol 2003; 31: 1348-1356, doi: 10.1016/j.exphem.2003.08.014.

34. Zhang $\mathrm{H}$, Zhai $Z$, Wang $\mathrm{Y}$, Zhang J, Wu H, Wang $\mathrm{Y}$. Resveratrol ameliorates ionizing irradiation-induced long-term hematopoietic stem cell injury in mice. Free Radic Biol Med 2013; 54: 40-50, doi: 10.1016/j.freeradbiomed. 2012.10.530.

35. Neukirchen J, Fox F, Kündgen A, Nachtkamp K, Strupp C, Haas $R$, et al. Improved survival in MDS patients receiving iron chelation therapy - a matched pair analysis of 188 patients from the Dusseldorf MDS registry. Leuk Res 2012; 36: 1067-1070, doi: 10.1016/j.leukres.2012.04.006.

36. Kalinowski DS, Richardson DR. The evolution of iron chelators for the treatment of iron overload disease and cancer. Pharmacol Rev 2005; 57: 547-583, doi: 10.1124/ pr.57.4.2.

37. Buss JL, Torti FM, Torti SV. The role of iron chelation in cancer therapy. Curr Med Chem 2003; 10: 1021-1034, doi: 10.2174/0929867033457638.

38. Sampaio AF, Silva M, Dornas WC, Costa DC, Silva ME, Dos Santos RC, et al. Iron toxicity mediated by oxidative stress enhances tissue damage in an animal model of diabetes. Biometals 2014; 27: 349-361, doi: 10.1007/s10534-0149717-8.

39. Lescoat G, Chantrel-Groussard K, Pasdeloup N, Nick H, Brissot $P$, Gaboriau F, et al. Antiproliferative and apoptotic effects in rat and human hepatoma cell cultures of the orally active iron chelator ICL670 compared to CP20: a possible relationship with polyamine metabolism. Cell Prolif 2007; 40: 755-767, doi: 10.1111/j.1365-2184.2007.00468.x.

40. Rahal A, Kumar A, Singh V, Yadav B, Tiwari R, Chakraborty $\mathrm{S}$, et al. Oxidative stress, prooxidants, and antioxidants: the interplay. Biomed Res Int 2014; 2014: 761264, doi: 10.1155/ 2014/761264. 